\title{
Cognitive Context’s Role in Discourse Production
}

\author{
Lihong Shen \\ English Department, Hebei United University, Tangshan, China; \\ Communication University of China, Beijing, China
}

\begin{abstract}
Relevance Theory's unique view about context is cognitive context, which is dramatically different from the traditional view on context. Cognition varies with each individual so different people will produce different texts even though they are in the same social and cultural context. This paper is dedicated to the studies of cognitive context's role in discourse production.
\end{abstract}

Index Terms-relevance theory, cognitive context, discourse production, mental schema, cultural schema

\section{INTRODUCTION}

Relevance Theory is the core theoretic basis of cognitive pragmatics. In the framework of this theory, Sperber \& Wilson point out that cognitive context is a set of assumptions stored in human being's brain, commun ication is an ostensive-inferential process and language users abide by the principle of relevance. To the writer/speaker, communication is an ostensive process, that is, to present his communicative intention as clear as possible. To the hearer/reader, communication is an inferential process. According to the ostensive behaviour of the speaker/writer, the hearer/reader achieves the communicative intention combining the linguistic form with contextual assumptions.

According to Relevance Theory, cognitive context varies according to different individuals, for they have different experiences and live in different environments. All of these aspects will play a very important role in the process of discourse production. As a result, we can use different kinds of texts to express the same idea. In order to communicate with each other successfully, the speaker/writer will produce appropriate text for the communication. The production of discourse consists of two kinds of activities: interior mental activity and exterior communicative activity. Communication, which sometimes involves specific behaviour, is the social activity in connection with special objects. Communication has the following same aspects as the other practical and mental activities. Firstly, they have their own special structure and aim at solving some problems or fulfill some tasks. Secondly, they have the social goal. Thirdly, communication, which is the same as other human activities, needs tools or means to fulfill its intention. This kind of tool or means is acquired by the individuals during the socialized process and is developed or improved in diffe rent practices in society. Diffe rent from other human activities, co mmunication is aiming at hu man being, so communication is a cooperative and interactive behaviour from the beginning of its production and is based on social status and the relations among the people who live in the same society.

This interactivity is the important symbol of the communication. It is a special behaviour that is affected by different aspects and relations between the participants. Usually text is considered as the finished product. In fact it is a dynamic and creative activity in which people can finish or fulfill some social goals in certain situation.

Different individuals will learn something about the objective world in the natural and social environment through social division of labour. The world knowledge or encyclopaedic knowledge that is acquired by different people will be different both in depth or range and will reflect their value judg ments. The producer of the text should know how much information is involved in a special communicative situation. Only by knowing this can make the receiver achieve his intentions, that is to say, the producer of the discourse should know what kind of discourse is appropriate in a situation and what kind is not.

Different people have different experiences and are affected by different cultures and some factors in the society. According to different experiences, different structurized cognitive conte xt factors come into being. All of these factors will influence the individual's production of the discourse.

\section{MENTAL SCHEMA AND SOCIAL-PSYCHOLOGICAL REPRESENTATION IN COGNITIVE CONTEXT AND CHARACTERISTIC} STYLES

The definition of style is that it is the "trace of the context in the text."(Van. Dijk) From cognitive point of view, contexts vary according to different individuals for they have different experiences and live in different environments with different cognitive abilities. According to cognitive linguistics, all of these aspects play a role in forming a schema in human being's brain. Yule holds that schema is the structurization of the knowledge structure in mind.(1996) In the process of discourse production, different individuals have different mental schema in their minds and lead to different characteristic styles. 
Individuality is very important for the varied and colorful social life. As a result of individuality, communication among human beings has its own distinguishing character and becomes various and complex. Under the general condition, people can use the same language for different kinds of communication. Different social communities and individuals can choose the same language for communication but it is not necessary for them to choose the same language behaviour and means, thus different kinds of dis courses come into being. Anderson et al (1977) proves that different experiences, interests, gender etc. form different mental schemas in human being's mind even though they are affected by the same culture and further produce a higher level schema to help people 'see' the information. For example, as two famous writers in 1930s, Luxun's style is dramatically different from Xuzhimo's.

As the ordinary people, they also have their unique way to express the same ideas. For different communicative situations and different addressees, they can choose either direct or indirect ways to express their intentions; different syntax, lexical items and different semantic structures will be selected for expressing the same intention. Choice of style is something that no speaker or writer can avoid. From Sperber \& Wilson's point of view, the participants in the communication must obey the principle of relevance. So style arises, we maintain, in the pursuit of relevance. In aiming at relevance, the speaker must make some estimations about the hearer's cognitive abilities and contextual resources, and in particular in what she/he chooses to make explicit and what she chooses to leave implicit. The following examples are a set of discourses that required by the owner of the telephone when they are not in.

(1) a. Hello, you've reached Jim and Sara. We can't pick up the phone right now, because we're doing something we really enjoy. Sara likes doing it up and down, and I like doing it left to right. So leave a message, and when we're done brushing our teeth, we'll get back to you.

b. Hi, I'm not home right now but my answering machine is, so you can talk to it instead. Wait for the beep.

c. Please leave a message. However, you have the right to remain silent. If you give up the right, everything you say will be recorded and will be used by us.

d. Hey, maybe I am too weak to catch the telephone. Please open your mouth to speak something. it's you.

e. Hi. I a m probably home. I'm just avoiding someone I don't like. Leave me a message, and if I don't call back,

f. Hi, this is George. I'm sorry I can't answer the phone right now. Leave a message, and then wait by your phone until I call you back.

(cited from Chen Rudong, Cognitive Rhetoric)

These examples certain ly demonstrate that communication has social and emotional dimensions. In these examples, someone asks the caller to leave a message; someone has some requirements to the caller; someone asks the caller to leave a message meticu lously; someone shows the attitude to the caller; s omeone tells the caller how to leave a message and so on. From the perspective of the style, some speak without reservation; some speak tactfully, some speak humorously; some speak seriously...

Bartlett (1932) claims that the memory of text doesn't base on direct reproduction but construction. The production of discourse is also constructive; the writer/speaker combines the language knowledge and his /her own mental schema to construct new mental representations.

In the common spoken communication, the individual's mentality can be showed as the language character; in the written communication, it can be showed as the individual's style of the discourse. Participants need to constantly monitor the other participants as well as the other elements of the context and adapt their context models accordingly in order to be able to participate appropriately and competently. (van. Dijk.)

For example:

(2) In the spring of 1942, Chinese writer Duanmu Hongliang lived in Guilin. Everyday a lot of the young people who were interested in literature visited him. In order to devote himself to writing, he wrote a poem and put it on the door. It says: “.女儿心上想情郎, 日写花笺千万行, 月上枝头方得息, 梦魂却又到西厢。”

(3) At the age of 92, Liang Shuming, a very famous scholar, put a notice on his door in order to avoid the interruption of the visitors. It says:

“漱溟今年九十有二, 精力犹衰, 谈话请以一小时为限, 有未尽之意, 可以改日续谈, 敬此陈情, 唯希鉴谅幸 甚。

1986 年 3 月梁漱溟敬白”

(cited from Chen Rudong, Cognitive Rhetoric, 2001)

The two examples are the discourses that the hosts decline to receive the visitors. Both of them perform the act of refusing, but each of them has their own characters. The structures of these two discourses are utterly different. Example (2) was written in the form of a love song. Its rhyme and rhythm is sweet and soft and gives one much food for thought. The girl is in love with her boyfriend so passionately that she goes on writing the letter all day and all $\mathrm{nigh} \mathrm{t}$. By the implication of this love song, the visitors will receive the information that the writer is very busy and it is impolite to interrupt him. In example (3), the writer also uses the discourse to tell the visitors not to disturb him. His language, frank and honest, is like the daily conversation. The readers will be moved by the writer's sincere and earnestness. The notice not only includes such information as the age and energy of the writer but also shows the writer's attitude and requests to the visitors. Both of the examples perform an act of refusing but their styles are utterly different. The mental 
schemata of the two writers are different and the potential readers they will communicate with are also different. The example (2) was written by a famous writer Duanmu Hongliang in Guilin when he was 30 years old and the example (3) was written by Liang Shuming at the age of 92 in 1986. Owing to their different ages, their attitudes to society and life are different. The potential readers of the example (2) and the example (3) are different too. The former are the young people who like literature and the latter are all kinds of people in society so their mentalities are different. As a result, the style of the discourse is dramatically different though they perform the same refusing act.

\section{CUlT URAL SCHEMAIN COGNIT IVE CONTEXT AND DisCOURSE PRODUCT ION}

Saussure (my translation) puts forward that the custom and culture of a nation will be reflected in their language. On the other hand, to some extent, it is language that form the nation. The culture and custom the people live in are branded on one's mind forever. As the mental character and common tendency, the mentality of a nation controls the tendency of a nation's behavior. It includes feeling, value, moral consciousness, relig ion and so on. People from different cultures form different cultural schemata in their mind. Language is the product of society so every aspects of language are associated with certain social culture and consciousness closely. It influences how to choose and construct the information in a text. That is, culture heavily influences discourse styles in systematic ways and the rules generated by culture determine the underlying structure of conversation. (Steven M. Hoenisch,1998) For example, English, American, Japanese and Chinese will write a letter in different forms. Chinese and Japanese write the address of the letter from "the big" to "the small", from "the far" to "the near", from "the macro" to "the micro", from "the vague" to" the specific", however, English and American write it in an utterly different order. Just because of different cultures and customs the people live in, their constructions of text vary according to their different cultural schemata in cognitive context.

When people receive a compliment, the westerners will say “Thank you”, while the Chinese are likely to say “惭愧, 惭愧 (I’m shamed)” or “您过奖了 (You flattered me)”.For example, one day, you wear a beautiful dress. People will say: "How beautiful your dress is!". Hearing this, the Japanese and Chinese will say: "No, I have worn it for several years.” Or “那里, 那里”. On the contrary, the A mericans will say: “ Thank you, it is bought by my mother.”

In the western society, they do pay no attention to the difference between the old and the young. While Chinese have a restriction on the role of discourse, for example, Chinese say：“您老辛苦了 ”or “您老当心 ” to show their respects to the old but the westerners do not. Let's look at the following example:

(4) Cooper: Hey, Wang, I hear you just have a paper published. I'd like to take you and Zhou out tomorrow evening to dinner to celebrate. How about it?

Wang: Oh, no. That's really not necessary. Why don't you come over and have dinner with us?

Cooper: I wouldn't hear of it. On my birthday you made me the best Chinese dinner I've ever had. I'm not much of a cook myself, but it would give me great pleasure to take you both out to eat. You choose any kind of food you'd like.

Cooper and Wang are colleagues. They address each other in a casual way. Cooper addresses "Wang" directly and doesn't add "LAO" before "Wang". If the conversation is between two Chinese, the words that indicate the difference between the old and the young will be added to the surname.

In the communication, A mericans always put forward the requirements straightly and then the polite expressions. On the contrary, Japanese put a lot of polite expressions before their requirements. When Americans read the letter from Japanese, they will read from the end to the beginning, so do Japanese read the letter from A mericans. Different cultures and customs influence the cognitive context of the people. As the result, they will influence the construction of discourse.

\section{FRAME AND KNOWLEDGE SCRIPT IN COGNIT IVE CONTEXT AND DISCOURSE PRODUCTION}

\section{A. Omission in Discourse Production}

Minsky (1975) puts forward that our knowledge is stored in the memory in the form of data to construct different frames. These frames represent models of situation. The writer/speaker has acquired some conventional knowledge from his/her experiences in society. These conventional knowledge constitutes different "frames" in their mind. The frame will influence the production of discourse. When one of the frames is activated, the addressor will have a lot of assumptions about it, that is, what the people will do and what are included in it. For example, when the classroom is mentioned, the reader/speaker will think about the desk, the chair, the teacher and the student. The "classroom" can stimulate the whole frame that consists of a lot of relevant things. It is not necessary to describe all of the things in a classroom. Indeed, precisely because the reader/hearer are normally able to supplement information in discourse with their own activated, inferred or otherwise construed personal or social knowledge, discourses need not be very explicit. For example:

(5) The sound of reading is from the classroom.

Hearing this, the reader/hearer will have a scene in his mind: the students are sitting on the chair and reading the book. Look at another example:

(6) She went to the hospital by taxi. 
In this example, it is not necessary for the writer/speaker to tell the following steps: first, she called a taxi and got into it, then got off from it. The reader/hearer can understand it clearly without the detail description of the whole process. Owing to the "frame", the addressor can omit some information in the communication and the reader/hearer can complement it unconsciously. Given a speaker who wants to tell a story about a personal event, a journalist having to write about a political event, or a scholar writing a research paper, they are all confronted with mental and practical task what information they have about the events talked about should be expressed, and what should not or need not expressed in their actual text or talk. It seems obvious that the strategies managing this selection are based on information supplied by the cognitive context of the speaker/ writer.

(7) Woman: Have we spoken to everyone?

Man: I've spoken to his friend and if you have seen all his family, I suppose we can go.

Woman: Yes. I expect they want to be alone now.

In this example, both husband and wife know conventional knowledge about the funeral. There are shared assumptions about the funeral in their cognitive contexts. In the communication, they can omit a lot of information about the shared assumptions in this frame. Let's try to complement all of the o mitted information in the conversation.

(8) W: (M1) (We should have spoken to everyone before we leave) Have we spoken to everyone?

M: (M2) (Yes, I think we have.) I've spoken to his friend and if you've seen all his family. (M3)(then we've spoken to all his family and friends.)I suppose we can go.

W: Yes, (M4) (I think so. We should be going at once because) I expect they want to be alone now.

However, the example (8) sounds redundant as the conversation between wife and husband. Owing to some shared frames or knowledge scripts, people can omit some elements in discourse production to communicate effectively.

\section{B. Lexical Choice in the Process of Discourse Production}

From cognitive point of view, the words in a frame must be relevant to one another, otherwise, they will sound unacceptable. For example, if we want to describe a mental state of sadness, the words selected must be relevant to the theme of the discourse because people can't mingle different feeling into one in their cognitive contexts.

According to relevance theory, the writer/speaker will help the addressee acquire the most relevant explanation with least effort. When a word is considered as the theme of the discourse, the other words must be relevant to it. If the other words are irrelevant to it, the discourse will be difficult to be understood no matter how many efforts the addressee takes. The whole discourse will sound ridiculous. While producing the discourse, there are a lot of assumptions in the addressor's mind, for example, the assumptions about "who", "where", "what", "when" and the like in a narration and the word about these assumptions must be relevant to the theme word though they are not determined. By choosing the words correctly can the effective discourse be constructed. For example:

(9) a. It is a good textbook. The content is new.

(9) b. It is a good textbook. The engine is strong.

(9) b sounds ridiculous because engine is irrelevant to the textbook.

\section{Spatial Order and Discourse Production}

Living in the society, human being has its special cognition about the space. All of these assumptions about "spatial order" are stored in their brain to form different spatial frames. They will obey the spatial order when they produce the discourse about the space. The spatial order includes "from the high to the low", "from right to left" or vice versa. Here is an example:

(10)My house consists of two floors: the ground floor and the first floor. On the ground floor there is the dining-room, the lounge or sitting-room, the kitchen and the hall. In the hall we keep a stand for hats, coats and umbrellas. A staircase leads fro $m$ the hall to the landing on the first floor. On this floor there are four bedrooms, a bathroom and lavatory...

If this kind of discourse is not constructed according to certain spatial order, it will be difficult to be understood.

\section{ADDRESSOR's EST IMATION OF THEADDRESSEE's COGNITIVE CONTEXT AND DISCOURSE PRODUCT ION}

According to Sperber and Wilson, communication is a process in which people attempt to receive communicative effects by taking least effort as possible as they can. (Sperber $\&$ Wilson,1995). In order to commun icate with each other smoothly, the addressor continues to estimate on the cognitive context of the addressee. By this estimation, he will try his best to construct appropriate discourse for successful communication. He should know who he is, as what he is present, for whom he is speaking, and so on. For example, parents speak differently to children than to adults, women differently to other wo men that to men.

If he can not have a correct estimation of the addressee's cognitive context, the communication will be a failure or bring about the feeling of humor. That is, the cognitive context defines the way in which language users socially self-define the ms elves and other participants in the present communicative situation.

Chinese has two styles: classical style of writing and the vernacular of writing. In the past time, only the people who had studied in the old-style private school spoke and wrote in classical style of writing. If people speak to the illiterate in classical style, the communication would not be successful or full of hu morou sness.

For example: 
(11) Once upon a time, there was a son of a rich man who owned a big shop. The son was so stupid that he learnt nothing in the private school. One day, several visitors came to visit his parents. Just at that moment the son was in the shop, so the visitors asked: "Is your 'Lingzun' in?". The son answered, “ No". Then the visitors asked again, "Is your 'Lingtang' in?" The son answered, "Ling zun and Lingtang are not available in our shop."

In classical style of Chinese, "Ling zun" and "Lingtang" mean father and mother respectively. The foolish son did not know this. What he knew was that he was in the shop to sell the goods to the customers. When the visitors asked if his "Lingzun" and "Lingtang" were in, he thought that they wanted to buy some goods called "Ling zun" and "Lingtang". The son is foolish enough to be laughed at, however, the visitors in this joke did not receive the information they wanted to get. From this joke, we can see that the wrong estimation of the addressee's cognitive context will lead to the failure of the communication.

There is another example:

(12) One day a work team went to a faraway village to take a census. They asked an old woman: "Do you have spouse?" Hearing this the woman was astonished because she didn't know what the word "spouse" meant. In her cognitive context, there was not the definition of "spouse", so she could not understand the meaning of the question. Of course the investigator also could not receive the information he wanted. Then he continued to ask the woman: "Do you have husband?" The woman answered: "Yes". The communication was fulfilled success fully.

Only by the correct estimation of the addressee's cognitive context can the addressor produce the adequate discourses for successful communications. If the addressor makes sure that the addressee has mastered the key information about the thing, he will omit a lot in the construction of discourses because these information have been known by the addressee. Considering the addressee's cognitive context in different situations, the addressor will adopt effective ways to express his communicative intentions.

For example:

(13) A: What time is it?

B: The milkman has just arrived.

This is a classical example in the discourse analysis. In this example A wants to know what time it is, but B does not answer his question directly. If the communication is successful, it means that both A and B know that the milkman always comes here at a certain time and B knows that A knows it. According to the second principle of relevance: that the presumption of optimal relevance is ostensively communicated. It claims that the act of communication is relevant to the addres see. By answering indirectly, the speaker encourages the hearer to speculate on - perhaps draw conclusions from - a piece of information that she would not have derived from the direct answer. Before producing the discourse, B evaluates that A has "the information"(the milkman always comes here at a certain time) in his cognitive context, that is to say, B knows that A can understand his answer correctly. If B thinks that A does not know this fact, he will answer in another way (It is eight.).

\section{COGNITIVE CONTEXT AND ARRANGEMENT OF INFORMATION IN DISCOURSE}

\section{A. Salience in the Cognitive Context and Discourse Production}

When the writer/speaker describes or narrates something, the salient character of the thing is in their cognitive context. Depending on our cognitive ability to direct our attention, different aspects are highlighted, resulting in different linguistic expressions. The user of language tells us what's going on in their minds when they produce the words and sentences. During the process of producing the discourse, which information will be included in a summary, abstract, lead, title or headline, which information will be placed first or last, does not only depend on the conceptual or semantic importance of the propositions, but also on their contextually determined prominence or importance. They will put the most salient aspects in an important position. They write/speak it first and then other things.

The order of prominence of propositions in discourse is also a function of relevance. That is, information that is relatively and contextually important, that is relevant to the speech participants, may generally be expressed first, on top, or in special discourse categories such as titles or summaries, or be repeated several times.

For example:

(14) a: John hit Mary in the face.

(14) b: It was John who hit Mary in the face.

(14) c: It was in the face that John hit Mary.

(14) d: It was Mary that John hit.

(14) a just tells us a fact that John hit Mary. (14)b, (14)c and 14)d stresses the different salient points respectively. Though the basic meaning of these sentences is the same, but the most important information the writer/speaker wants to transform is different. Another example cited fro m Liao Qiu zhong(1988):

(15) a. 眼镜蛇: 为我国著名的毒蛇之一, 因颈部有一对白边黑心的眼睛状斑纹而得名。遇敌时, 前半身坚起, 颈部膨大, 斑纹醒目。具沟牙; 分布于我国长江以南各省。(《中学生生物实用大全》)

(15) b. Cobra is one of the famous kinds of poisonous snakes in our country. It has its name for the white and black glasses-like stripe in the neck. When it meets enemies, the upper body erects, the neck expands and the stripe becomes striking to the eye. It has groove-like teeth and is distributed over the places on the south of the Yangtse river. (my 
translation)

In this example, glasses-like stripe and groove-like teeth can stand for the cobra, so in the description of cobra, people will put the special point in an important position. Compared with the glassed-like stripe, groove-like teeth is less important, so it is put after the former.

\section{B. Old Information and New Information}

The content of the discourse includes the old and new information. Because of the linear character of the language, the writer/speaker must consider the order of the language structure while transforming information. Within the framework of relevance theory, the order is restricted by cognitive context. The arrangement of language structure must obey the principle: from "the old" to "the new", from definite things to indefinite things. For example:

(16)The king went to have his breakfast. He took a cup of milk, but it immediately turned to gold. Then he took a piece of bread, and that also turned into gold.

In this example, "the king", the starting point of the sentence, has been mentioned in the preceding part of the text. It is old information. "went to have his breakfast", which is not mentioned in the above text, is new information. In the first clause of the second sentence, "he" refers to "the king" that has been talked about before, so it is the old information. In the second clause, the word "it" which means "a cup of milk" in the first clause, is old information. "immediately turned into gold" is the new content that the writer wants to transform to the reader, so it is the new information. From the above analysis, we know that the structure of the discourse obeys the rule of "from old information to new information".

\section{THE ADDRESSOR's INTENTION AND DISCOURSE PRODUCTION}

According to relevance theory, the addressor has both informative intention and communicative intention in the communication. For example, A asks: "Can you tell me how I can get to the railway station?" The informative intention is the literal meaning of the sentence. The communicative intention is that he wants help. In different communicative fields, addressors will construct different discourses for different intentions. The communicator's intention decides her/his discourse strategy. For example, in a personal letter, personal experience and interesting things will be involved. In a business letter, the discourse will be constructed in a different way. Look at the following examples:

(17) a. I wonder whether you can come?

(17) b. I wondered whether you could come?

(17) c. I am wondering whether you can come?

(17) d. I was wondering whether you could come?

The above sentences are different in the form of "time" and "aspect" and reflect the addressor's different communicative intentions respectively.

(18) a. Can you help me?

(18) b. Could you help me?

(18) c. Will you help me?

These sentences also reflect the subtle difference of the addressor's communicative intentions. Different communicative intentions can influence the production of the discourse.

\section{CONCLUSION}

With the rising of cognitive science, more and more linguists begin to take psychological factors or mental activities into account. As a new branch of linguistics, cognitive pragmatics comes into being accordingly, which gives rise to a dynamic notion of context: cognitive context. In the Relevance Theory put forward by Sperber and Wilson, the co-author claim that cognitive context is a set of assumptions stored in participants' mind rather than the pre-existed or shared knowledge before the communication or the objective facts before us. It is the cognition that is produced in the dynamic process of communication. The cognitive context lies in the fact that language users can actively manipulate, choose and produce a favourable context for discourse production and interpretation. In addition, according to Relevance Theory, both the manipulation and the choice of the context are based on mutual manifestness. As the production and inference of the information, communication is the process in which both the addressor and the addressee construct and choose the appropriate cognitive context for co mmunicating success fully.

\section{REFERENCES}

[1] Anderson. R.C. (1977). The Notion of Schemata and the Educational Enterprise. In R.C. Anderson. et al (eds). Schooling and Acquisition of Knowledge. Hillsdale, NJ: Lawrence Erlbaum. 415-431.

[2] Bartlett, F. (1932).Remembering: A Study in Experimental Social Psychology. Cambridge: Cambridge University Press.

[3] Hoenisch.Steven.M A Wittgensteinian. (1998). http://www.criticism.com. (accessed 11/7/2012).

[4] Minsky, M. (1975). A framework for representing knowledge in Winston, P. H. (eds.) The Psychology of Computer Vision. New York: McGraw-Hill, 211-277.

[5] Qiuzhong Liao. (1980) Liao Qiuzhong Anthology. Beijing: Beijing Lan guage College Press.

[6] Rudong Chen. (2001). Cognitive Rhetoric. Guangzhou: Guan gdong Education Publishing House. 
[7] Sperber,D. and D.Wilson.(1995). Relevance: Communication and Cognition. Oxford: Blackwell.

[8] Saussure, Ferdinand de. (1960). Course in General Lin guistics. Beijing: China Social Science Publishing House.

[9] van Dijk, Teun A. (1998). Cognitive Context Models and Discourse. in Maxim Stamenov (ed), Language.189-226.

[10] Yule, G. (1996). Pragmatics. Oxford: Oxford University Press.

Lihong Shen was born in Handan, China in 1978. She is a PhD candidate in lin guistics in Communication University of China. She is currently an associate professor in the School of Foreign Lan guages, Hebei United University, Tangshan, China. Her research interests include linguistics and literature. 